\title{
Autoinflation of saline-filled inflatable breast implants
}

\author{
Walter Peters PhD MD FRCSC
}

\author{
W Peters. Autoinflation of saline-filled inflatable breast \\ implants. Can J Plast Surg 2006;14(4):219-226.
}

Spontaneous autoinflation of saline-filled breast implants is a rare phenomenon; only 20 cases have been reported in the world literature. Over the past seven years, three patients have presented with significant unilateral autoinflation of their smooth, single-lumen, round, saline-filled implants. This developed at various times: progressively over 23 years with a Simaplast implant; between the ninth and 10th year after augmentation with a leaflet valve implant; and slowly over the first four years with a leaflet valve implant. The etiology of the autoinflation was shown to be different for the two types of implants. The Simaplast implant had likely been injected with a hypertonic filling solution - one that was twice as concentrated as 'normal saline'. This would have created an osmotic gradient, which would have facilitated autoexpansion by diffusion. The implant solution remained clear and transparent. In addition, there were no detectable levels of glucose, uric acid or albumin in the fluid. By contrast, auto-inflation of the leaflet valve implants likely resulted from mechanical alterations of the valve mechanism. This type of implant is known to have a high deflation rate, with frequent partial deflations. It is interesting that one of the patients with the leaflet valve implants presented with an autoexpansion on one side and a partial deflation on the other side. Both implants were from the same lot number. The same mechanism that caused partial deflations may have also allowed fluid from the implant pocket to pass through the valve into the lumen of these implants. This could allow glucose, protein and cellular elements to enter into the lumen (these would not pass through an intact elastomeric shell) which would create an osmotic gradient, allowing water to enter the elastomeric shell by diffusion. The fluid in these leaflet valve implants was brownish yellow, very viscous and turbid. It contained elevated levels of glucose and uric acid which would not have passed through the elastomeric shell. Over the past 10 years, four different theories have been proposed in an attempt to explain the etiology of autoinflation. However, the findings of the present study indicate that there are only two mechanisms - a hypertonic filling solution and alterations of the valve mechanism.

\section{Key Words: Autoinflation; Saline-filled breast implants}

\section{L'autogonflement des implants mammaires remplis de sérum physiologique}

L'autogonflement spontané des implants mammaires remplis de sérum physiologique est un phénomène rare, puisque 20 cas seulement ont été déclarés dans les publications mondiales. Depuis sept ans, trois patients ont présenté un autogonflement unilatéral important de leurs implants remplis de sérum physiologique ronds, souples et monolumières. Cette occurrence se déclare à divers moments : progressivement, sur une période de 23 ans, avec des implants Simaplast; entre la neuvième et la dixième année suivant l'augmentation mammaire avec des implants avec valve; et lentement, au cours des quatre premières années, avec des implants avec valve. L'étiologie de l'autogonflement différait selon les deux types d'implants. Les implants Simaplast avaient probablement été injectés d'une solution hypertonique, deux fois plus concentrée qu'un sérum physiologique normal. Cette solution aurait créé un gradient osmotique qui aurait favorisé l'autogonflement par diffusion. La solution était demeurée claire et transparente. De plus, le taux de glucose, d'acide urique ou d'albumine n'était pas décelable. Par contre, l'autogonflement des implants avec valve était probablement causé par des altérations mécaniques du mécanisme de valve. On sait que ce type d'implant s'associe à un taux élevé de dégonflement et à de fréquents dégonflements partiels. Il est intéressant de souligner qu'une patiente a subi un autogonflement d'un côté et un dégonflement partiel de l'autre. Les deux implants possédaient le même numéro de lot. Le mécanisme responsable du dégonflement partiel peut également avoir permis au liquide de l'enveloppe de l'implant de traverser la valve pour se loger dans la lumière. Ainsi, les éléments glucosés, protéiques et cellulaires ont pu pénétrer dans la lumière (ils n'auraient pas traversé une enveloppe élastomérique intacte), ce qui a créé un gradient osmotique permettant à l'eau de pénétrer dans l'enveloppe élastomérique par diffusion. Le liquide de ces implants avec valve était brunjaunâtre, très visqueux et trouble. Il contenait des taux élevés de glucose et d'acide urique, qui n'auraient pas traversé l'enveloppe élastomérique. Depuis dix ans, quatre théories ont été proposées pour expliquer l'étiologie de l'autogonflement. Cependant, d'après les observations de la présente étude, il n'existe que deux mécanismes : une solution de remplissage hypertonique et des altérations du mécanisme de valve.
In January 1992, the United States Food and Drug Administration announced a moratorium on the use of silicone gel breast implants in the United States (1). Health Canada quickly extended this policy into Canada, where it remained in place for eight years. In January 1992, the Italian Minister of Health took a different approach. He banned the use of single-lumen silicone gel devices, but allowed the use of double-lumen devices with silicone gel in the central core and saline in the outer lumen (2). In Italy, double-lumen devices, which had become old-fashioned, suddenly gained renewed popularity. They quickly became the most popular implant in the country. The first cases of autoinflated implants involved these particular double-lumen devices.

Spontaneous autoinflation of saline-filled breast implants is a rare phenomenon. An Italian study by Botti and Villedieu (3) first reported it in 1994. They described nine textured, double-lumen implants that underwent a significant, spontaneous volume increase in their outer lumens, two to 18 months after insertion. The manufacturer of these implants was not provided. In seven of the nine implants, the autoinflation was 
unilateral, and bilateral in the remaining two. In six of the implants, the liquid in the outer lumen was brownish yellow in colour and transparent in the other three implants. The liquid in the outer lumen of all of the implants was sterile and biochemically 'very similar to human serum'. They postulated that in the autoinflated implants, the exudate around the implant forced the lamellar valve and penetrated the outer lumen, where it became trapped. The resulting osmotic gradient led to volume expansion of the outer lumen.

In 1994, another Italian study by Signorini et al (2) described a similar phenomenon in three patients with four textured, double-lumen implants that had been in place for two to seven months. An unspecified French company manufactured all of the implants. All three patients had presented with a Baker class IV contracture. Their breasts were explored to address these capsular contractures. During the surgery, autoinflations were discovered. The volume of the outer lumen of these implants had increased from the original $20 \mathrm{~mL}$ to between $60 \mathrm{~mL}$ and $140 \mathrm{~mL}$. The autoinflation was unilateral in two patients and bilateral in one patient. In all patients, the outer lumen had inflated with a brownish yellow solution, which was very viscous and contained cellular debris and protein. It was 'very similar to interstitial fluid'.

Signorini et al (2) postulated that there were three potential causes of the autoinflation that could be acting simultaneously. First, they suggested that all of the outer lumens of the implants had initially been filled with a hypertonic solution, creating an osmotic gradient. Water could then enter into the outer lumen to increase its volume. Three of the implants had been in place for seven months and contained isotonic levels of sodium and chloride. Two other implants had been in place for two months and contained hypertonic levels of sodium and chloride. It was postulated that all of the autoinflated implants had originally been filled with a hypertonic solution, but that those in place for only two months had not been in place long enough to reach osmotic equilibrium. Second, it was postulated that the elevated concentrations of sodium chloride in the outer lumen of the implants may have been due to the salt that was used in the texturing manufacturing process. Third, because the fluid in the outer lumen contained glucose, proteins and cellular debris, they postulated that there was also a mechanical valve defect because these substances would not be expected to pass through the intact elastomeric shells.

In 1997 (4) and 1998 (5), Robinson and Benos, who had implanted more than 2000 saline-filled implants in the preceding 10 years, reported five patients who had received singlelumen, saline-filled, smooth implants. They presented with unilateral autoinflation, four to nine years after their original insertion. In four of the implants, the implant volume had approximately doubled. In the other implant, the volume had increased by only $16 \%$. The fluid in all expanded implants was brownish yellow and very viscous. All fluids were sterile on culture. These investigators hypothesized that the mechanism of this expansion was 'colloid osmotic swelling'. They suggested that over time, protein and glucose could penetrate through the elastomeric shell into the lumen of the implant. This would create an osmotic gradient, with water subsequently entering the implant, to produce the autoinflation.

However, in an 'invited discussion' section of Robinson and Benos' (4) paper, Frisch (6) stated that the glucose and protein concentrations in retrieved filling solutions were too low to affect water permeability into the shells. He thought that the autoinflated implants would not have been permeable to sodium chloride, and to the larger glucose and protein molecules. He concluded that none of these molecules would have entered the lumen by permeation through implant shells. He strongly disagreed with the hypothesis of 'colloid osmotic swelling'. In a subsequent publication, Frisch (7) concluded that the cause of the autoinflation in these patients was elevated concentrations of sodium chloride in the original filling solutions. He did not address the possibility of alterations at the valve level which could have allowed sodium chloride, glucose, protein and cellular elements to enter into the implants through the valves.

In 1999, a Turkish study by Tuncali and Ozgur (8) described the use of magnetic resonance imaging to measure in situ volumes of saline-filled implants. In 2002, another Turkish study by Ketene et al (9) described unilateral autoinflation in two patients who had received single-lumen, textured, highprofile, saline-filled implants. The volume expansion was noted six to 14 months after the initial surgery. In one patient, the implant had expanded from $255 \mathrm{~mL}$ to $295 \mathrm{~mL}$ with a viscous yellow fluid. In the other patient, the implant had expanded from $460 \mathrm{~mL}$ to $540 \mathrm{~mL}$ with a viscous brown fluid. In 2006, a Chinese study by Chien et al (10) described a woman with textured double-lumen implants who presented 15 years after breast augmentation, with a unilateral deflation and a contralateral autoinflation.

The present paper describes three patients who developed unilateral autoinflation; in the first patient, the autoinflation developed slowly and progressively over 23 years with a Simaplast implant; in the second patient, between the ninth and 10th year after augmentation with a leaflet valve implant; and in the third patient, progressively over four years from the time of augmentation with a leaflet valve implant. The four current theories concerning the etiology of autoinflation are described. Two particular theories are favoured to explain the findings in the present study.

\section{Case 1}

\section{CASE PRESENTATIONS}

A 44-year-old woman requested the removal of her saline-filled implants and replacement with new implants because the left breast had become painful, firm and progressively larger over the years. She had originally undergone a bilateral, inframammary, subglandular breast augmentation 23 years earlier, using Simaplast 16/10 implants (Simaplast Company, Toulon, France). The right breast was smaller, so it had been filled to a volume of $220 \mathrm{~mL}$, whereas the left was filled to $200 \mathrm{~mL}$. The operative report stated that the filling was 'saline solution'. The surgeon had instilled $50 \mathrm{mg}$ of Kenalog (Bristol-Myers Squibb Canada) into each pocket. The patient recalled that the left breast became firmer and larger within one year, and had become progressively firmer and larger over the subsequent 22 years. Fifteen years after her surgery, she breastfed her son uneventfully for 14 months. Currently, the left breast was noticeably larger than the right (Figure 1). There was a Baker class II contracture on the right side and a Baker class IV contracture on the left side.

At explantation, both implants were clinically intact (Figures 2 and 3). The left implant was larger than the right (290 mL versus $220 \mathrm{~mL}$, respectively). There was a thick layer of calcification covering most of the anterior surface of each implant (Figure 3). The calcification on the left side was much 


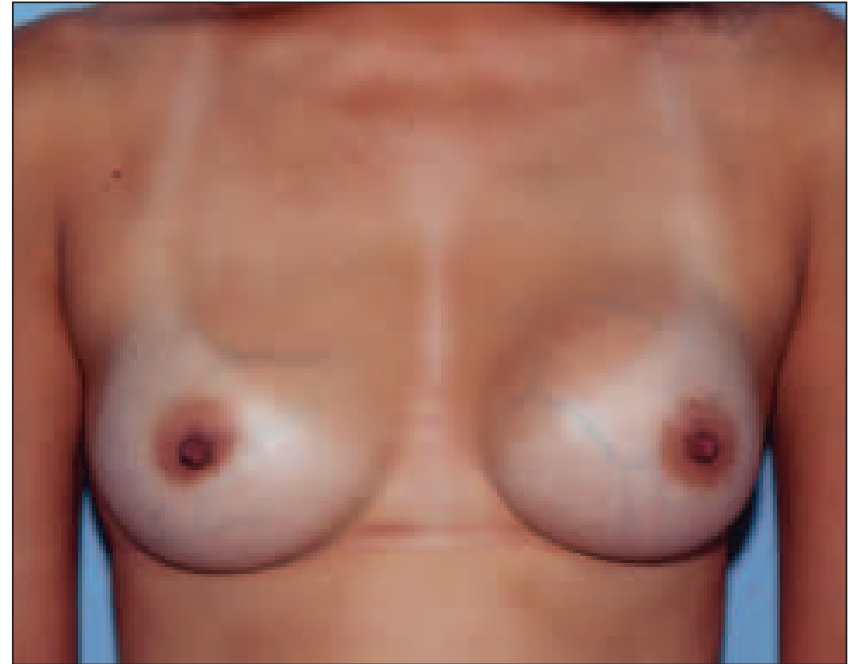

Figure 1) Case 1 - The appearance of a patient 23 years after subglandular augmentation with Simaplast implants. The left breast is larger than the right. There was a Baker class II contracture on the right side and a Baker class IV contracture on the left side

more extensive than that on the right side. Posteriorly, where the valve was located, there was no calcification (Figure 2). The capsules were resected bilaterally. Histologically, the anterior capsule showed pinpoint flecks of calcification within the capsule tissue. There was no calcification in the posterior capsule. New $275 \mathrm{~mL}$, Mentor (Mentor Medical Systems Canada Inc) style 1600, inflatable implants were inserted and were filled to a volume of $300 \mathrm{~mL}$. The patient made an uneventful postoperative recovery. She had excellent symmetry and a bilateral Baker class I result three years postsurgery.

The osmolality of the fluid in the right Simaplast implant was $304 \mathrm{mmol} / \mathrm{kg}$ compared with $407 \mathrm{mmol} / \mathrm{kg}$ on the left side (normal $280 \mathrm{mmol} / \mathrm{kg}$ to $300 \mathrm{mmol} / \mathrm{kg}$ ) (Table 1). The sodium and chloride concentrations on the right side were $160 \mathrm{mmol} / \mathrm{L}$ and $153 \mathrm{mmol} / \mathrm{L}$, respectively, compared with $215 \mathrm{mmol} / \mathrm{L}$ and $202 \mathrm{mmol} / \mathrm{L}$ on the left side. The $\mathrm{pH}$ was 5.9 on the left side and 6.0 on the right side. Further biochemical analyses showed that the following assays of the fluid in both implants were below detectable limits: albumin, glucose, total protein, calcium, carbon dioxide, creatinine, potassium, magnesium, phosphorus and uric acid.

Broth cultures from the right capsule grew Staphylococcus epidermidis. There was no growth from the left capsule. Cultures from the fluid inside the implants grew Staphylococcus cohnii from the left side, and S cohnii, Proprionibacterium acne and diphtheroid bacilli from the right side. All cultures of the capsules and fluid inside the implants were negative for fungi.

\section{Case 2}

A 30-year-old woman requested the removal of her salinefilled implants because the left breast had become painful, firm and progressively larger over the preceding 1.5 years. She had originally undergone a bilateral, inframammary, submuscular breast augmentation 10 years earlier, using bilateral $300 \mathrm{~mL}$, Mentor style 1800, smooth, round, single-lumen leaflet valve implants. The left breast was smaller, so the left implant was filled to a volume of $330 \mathrm{~mL}$, whereas the right implant was filled to $300 \mathrm{~mL}$.

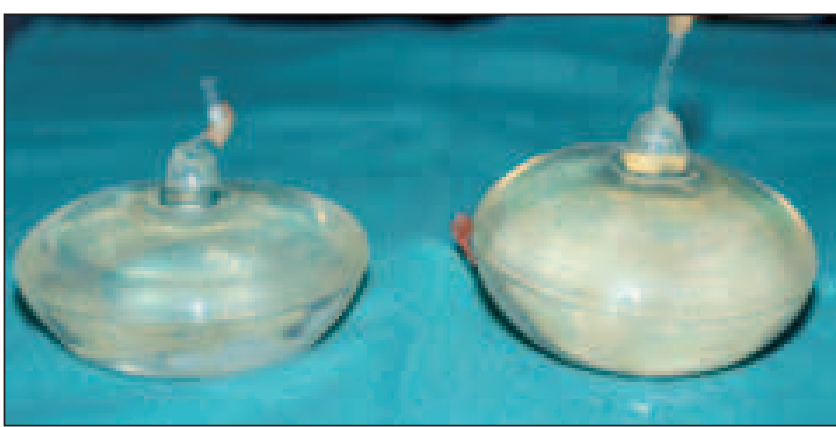

Figure 2) Case 1 - The posterior surface of Simaplast implants removed after 23 years in situ. The patient's left implant had expanded $45 \%$ from $200 \mathrm{~mL}$ to $290 \mathrm{~mL}$. The volume of the right implant was unchanged $(220 \mathrm{~mL})$. A filling tube is permanently attached to the posterior surface of the implant and a Teflon plug provides a watertight seal. After filling the implant, the tube is buried into a pocket in the posterior aspect of the implant so that it is concealed

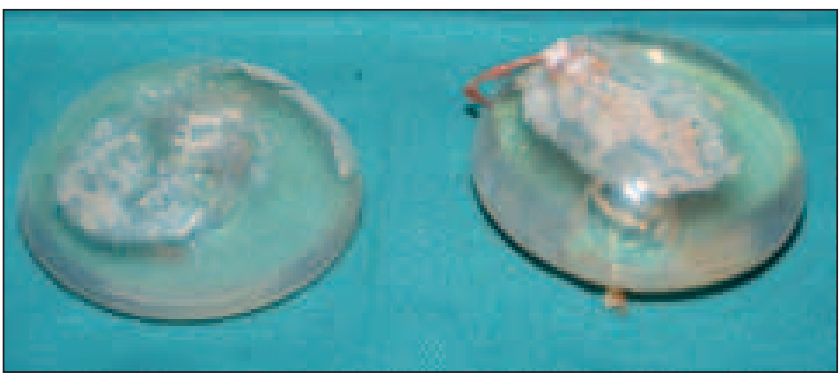

Figure 3) Case 1 - The anterior surface of the Simaplast implants removed after 23 years in situ. A thick layer of calcification covers most of the anterior surface of the implants. The calcification is heavier on the left side, where there was a Baker class IV contracture. This could have caused a greater abrasion to the surface, resulting in more extensive calcification than that on the right side

TABLE 1

Data on the three autoinflated saline-filled implants

\begin{tabular}{lccc}
\hline & \multicolumn{3}{c}{ Implant type } \\
\cline { 2 - 4 } & $\begin{array}{c}\text { Simaplast } \\
\text { (Case 1) }\end{array}$ & $\begin{array}{c}\text { Leaflet valve } \\
\text { (Case 2) }\end{array}$ & $\begin{array}{c}\text { Leaflet valve } \\
\text { (Case 3) }\end{array}$ \\
\hline Initial volume $(\mathrm{mL})$ & 200 & 330 & 280 \\
Final volume $(\mathrm{mL})$ & 290 & 620 & 418 \\
Volume gain $(\%)$ & 45 & 88 & 49 \\
Time of gain & Over 23 years & From 9 to & Over first \\
& & 10 years & 4 years \\
Appearance of & Clear, & Brownish yellow, & Brownish yellow, \\
fluid & transparent & turbid & turbid \\
Viscosity & Watery & Very viscous & Very viscous \\
Osmolality (mmol/kg) & 407 & 296 & 303 \\
Sodium level $(\mathrm{mmol} / \mathrm{L})$ & 215 & 153 & 146 \\
Chloride level $(\mathrm{mmol} / \mathrm{L})$ & 202 & 131 & 129 \\
Glucose level $(\mathrm{mmol} / \mathrm{L})$ & - & 0.1 & 1.9 \\
Uric acid level $(\mu \mathrm{mol} / \mathrm{L})$ & - & 105 & 112 \\
Culture implant fluid & Positive & - & - \\
\hline
\end{tabular}

There was no detectable levels of albumin in the implants

Ten years after her initial breast augmentation, the patient presented because the left breast had became painful, firm and progressively larger during the preceding 1.5 years. The patient 


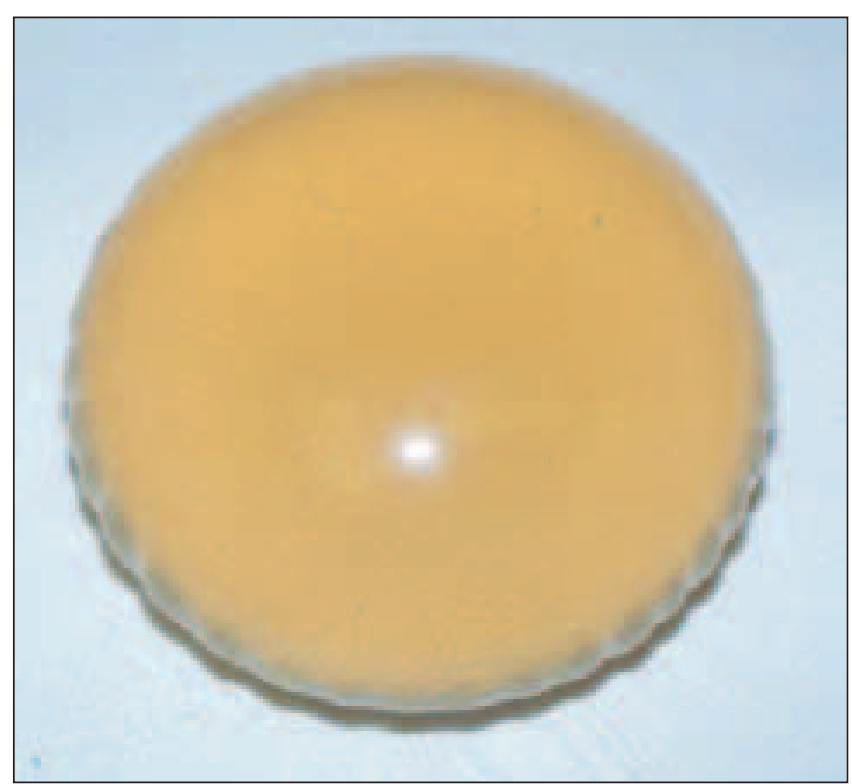

Figure 4) Case 2 - The left implant had autoexpanded $88 \%$ from $330 \mathrm{~mL}$ to $620 \mathrm{~mL}$. Note the peripheral scalloping of the implant wall. It was filled with a brownish yellow fluid that was very viscous and turbid. The right implant had not changed in size

had also gained $11.3 \mathrm{~kg}$ during the preceding 1.5 years. Examination at this time indicated that she had a Baker class II result on the right side and a Baker class IV result on the left side. A bilateral breast ultrasound study showed no focal cystic or solid lesions in either breast. The patient requested removal of her implants without any replacement.

At explantation, both implants were clinically intact. The left implant was larger than the right. The right implant was $305 \mathrm{~mL}$, whereas the left implant had autoinflated by $88 \%$ to $620 \mathrm{~mL}$ (Figure 4). There was peripheral scalloping of the implant because of the degree of expansion. Clinically, the left implant was filled with a slightly turbid, brownish yellow, very viscous fluid, which contained particulate material. By contrast, the fluid in the right implant appeared to be unchanged. It had remained clear and transparent.

The osmolality of the fluid in the left implant was $296 \mathrm{mmol} / \mathrm{kg}$ (normal $280 \mathrm{mmol} / \mathrm{kg}$ to $300 \mathrm{mmol} / \mathrm{kg}$ ) (Table 1). The sodium and chloride concentrations on the left side were $153 \mathrm{mmol} / \mathrm{L}$ and $131 \mathrm{mmol} / \mathrm{L}$, respectively, the glucose concentration was $0.1 \mathrm{mmol} / \mathrm{L}$ and the uric acid level was $105 \mu \mathrm{mol} / \mathrm{L}$. The albumin level was below detectable units. Broth cultures from the left and right capsules showed no bacterial growth. Cultures of the fluid inside the implants were negative for bacteria and fungi, and cultures of the capsules were also negative for bacteria and fungi.

\section{Case 3}

A 47-year-old woman requested the removal and replacement of her saline-filled implants because the right breast had become painful, firm and progressively larger since insertion. She had originally undergone a bilateral, inframammary, submuscular breast augmentation four years earlier, using $275 \mathrm{~mL}$, Mentor style 1800, smooth, round, leaflet valve, saline-filled implants, which were filled to $280 \mathrm{~mL}$ bilaterally. One month postoperatively, her breasts were symmetrical and the implants were still positioned somewhat high (Figure 5).

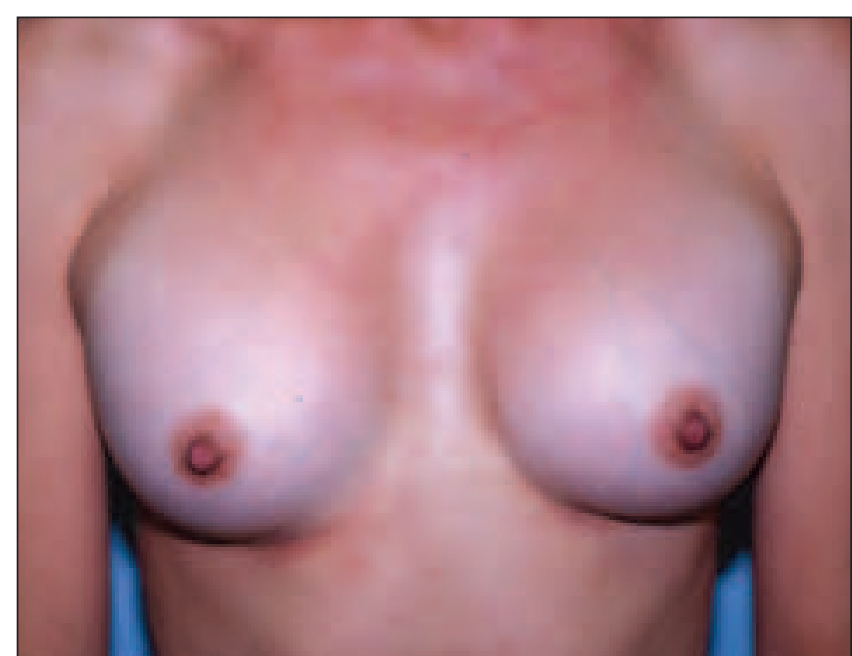

Figure 5) Case 3 - One month after breast augmentation, the breasts were symmetrical and the implants were still quite high

Four years after her original surgery, she presented with pain, firmness and progressive enlargement of her right breast (Figure 6). The left breast had a Baker class I result, whereas the right breast had a Baker class III contracture. At explantation, the right implant was clinically fully intact. It contained a very viscous, brownish yellow fluid (Figure 7). It had expanded to $418 \mathrm{~mL}$, an increase of $49 \%$ from the initial volume of $280 \mathrm{~mL}$. The osmolality of the fluid in the right implant was $303 \mathrm{mmol} / \mathrm{kg}$ (Table 1 ). The sodium and chloride concentrations were $146 \mathrm{mmol} / \mathrm{L}$ and $129 \mathrm{mmol} / \mathrm{L}$, respectively, the glucose concentration was $1.9 \mathrm{mmol} / \mathrm{L}$ and the uric acid level was $112 \mu \mathrm{mol} / \mathrm{L}$. Broth cultures from the implant fluid and the capsule were sterile on culture for bacteria and fungi.

The implant had partially deflated on the left side and weighed $150 \mathrm{~g}$. The fluid was clear and transparent. Both implants were replaced with new $275 \mathrm{~mL}$, Mentor style 1600, smooth, round implants which were inflated to a volume of $300 \mathrm{~mL}$. She made an uneventful postoperative recovery. Her breasts had no significant change over a subsequent three-year follow-up period.

\section{DISCUSSION}

\section{Simaplast implant}

The Simaplast implant (case 1, Figures 2, 3 and 4) was the first inflatable breast implant to be marketed commercially $(11,12)$. Dr HG Arion, a physics engineer and plastic surgeon in Toulon, France, developed it in the early 1960s. He patented it in 1964, and began using it clinically in 1965. In 1966, Roger Klein set up an American division of the company in New York and Massachusetts. Chas F Thackray Ltd marketed the implant in the United Kingdom and Real Laperierre Inc (Montreal, Quebec) marketed it in Canada.

The Simaplast prosthesis consisted of a silicone elastomeric shell, with a thickness of $0.50 \mathrm{~mm}$, with a filling tube permanently attached to the posterior aspect of the implant (Figure 2). After filling the implant, a Teflon plug was manually introduced into the filling tube to provide a watertight seal. The tube was then buried into a pocket on the posterior surface of the prosthesis so that it was concealed. Initially, Dr Arion suggested that the filling solution should be 


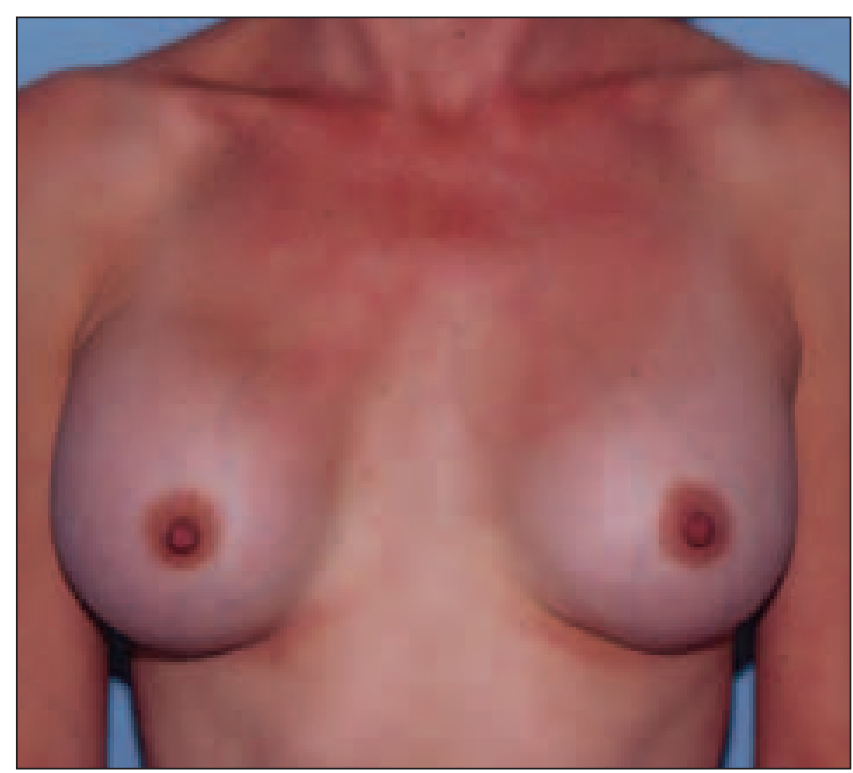

Figure 6) Case 3 - Four years after augmentation, the right breast had become progressively larger, firmer (Baker class III result) and painful. The left breast had a Baker class I result

a hypertonic solution, consisting of $6 \%$ dextran in normal saline. Subsequently, he recommended using normal saline alone $(13,14)$.

By 1967, approximately 500 patients had received these implants (11). In 1967, the Simaplast company was sold to the pharmaceutical firm Perdue Frederick Corporation (USA). There are only a few published reports describing the Simaplast implant in the world literature (12,14-16). In 1969, Tabari (15) described 30 cases of bilateral breast augmentation with $10 \%$ of those implants undergoing early spontaneous deflation. By 1972, Williams (14) reported a spontaneous deflation incidence of $76 \%$ for Simaplast implants within three years of implantation. Simaplast implants were then removed from the market. The total number of Simaplast implants that were distributed worldwide was only approximately 6000 pairs (HG Arion, personal communication).

\section{Etiology of autoinflation}

The exact etiology of autoinflation has not been well defined. It has been demonstrated that silicone elastomer is permeable to water (17) with a relatively high permeability coefficient compared with many other polymers. Measurements have shown that water will diffuse into an implant containing normal saline $(4,17)$ and it will diffuse from an implant containing a hypotonic saline solution into a surrounding normal saline medium $(18,35)$. The data under these two sets of conditions indicate that water gain or loss is linear, and is approximately $0.5 \mathrm{~g} /$ day when a significant concentration difference exists between the inside and outside of the shell. The rate falls progressively as the concentration difference diminishes toward equality.

The ultimate volume of a saline-filled breast implant is determined by the osmols of sodium chloride in the implant lumen. If the osmolarity of the filling solution differs from that of body fluids, then the volume and osmolarity of the filling solution will autoadjust by permeation of water into or out of

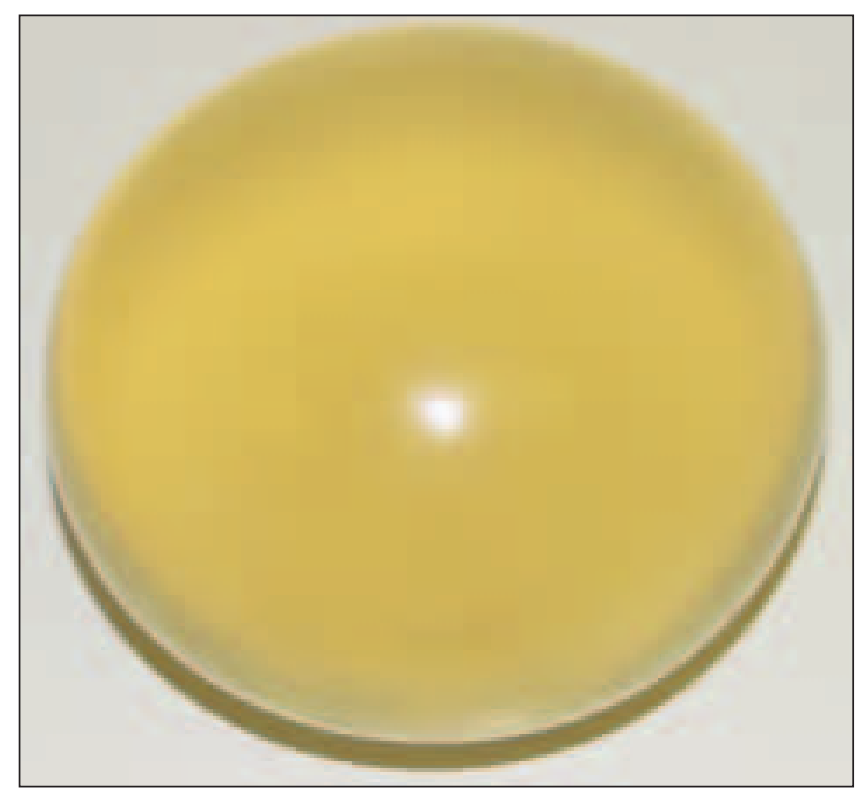

Figure 7) Case 3 - At explantation, the right implant had expanded $49 \%$ from $280 \mathrm{~mL}$ to $418 \mathrm{~mL}$. By contrast, the left implant had partially deflated from $280 \mathrm{~mL}$ to $150 \mathrm{~mL}$. The right implant was filled with a very viscous, somewhat turbid, brownish yellow fluid

the implant. Water permeation through the implant shell is always from low to high osmolarity. Equilibrium is reached when the osmolarities of the filling solution and the body fluids are equal (isotonic, $300 \mathrm{mOsm} / \mathrm{L}$ ). The implant size then becomes stable.

Analytical findings have shown that sodium chloride, glucose and protein cannot permeate through the elastomeric shell $(6,7)$. The main requirement for permeation is a molecular size that is smaller than the intermolecular spaces (pores) in the cross-linked elastomeric shell. These spaces are fixed by covalent bonds. Sodium chloride cannot enter implants through permeation because the sodium and chloride ions are too large to pass through the intermolecular spaces. In addition, if the implant shells were permeable to sodium chloride, then these implants would autodeflate rather than autoinflate. Sodium and chloride ions that permeated to the outer surface of shells would be removed by the dialysis action of body fluids, transported away from the shells and then eliminated by the body. Because the osmolarity of the filling solution decreased, water would permeate into the isotonic body fluids. The end result would be complete deflation.

Implant shells are not permeable to glucose molecules because they are larger than sodium and chloride ions. If implant shells were permeable to glucose, smaller sodium and chloride ions would permeate out, resulting in implant deflation. Albumin (molecular weight of $66,000 \mathrm{Da}$ ) is much too large to pass through the pores in the implant shell. In fact, it is 2800 times the atomic weight of sodium. Silicone elastomer has been extensively studied for controlled delivery of drugs (7). However, it has not been useful for the controlled delivery of proteins and polypeptides such as insulin (molecular weight of $5700 \mathrm{Da}$ ) or interferon (molecular weight of 30,000 Da). These drugs are simply too large to pass through the elastomeric pores.

Since 1994, four theories have been postulated in an attempt to explain the etiology of autoinflation: 


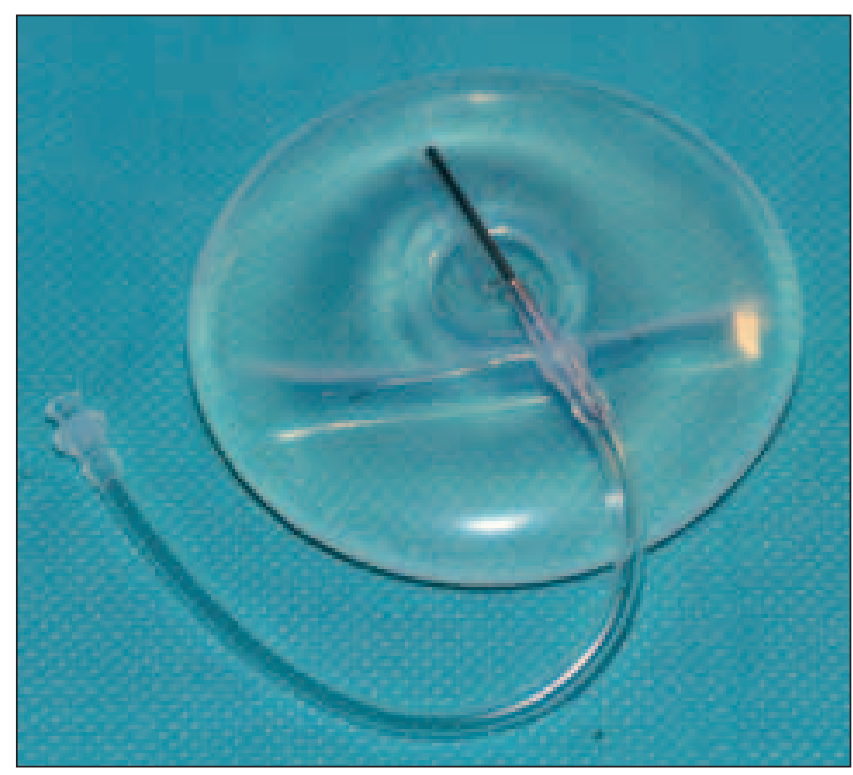

Figure 8) A Mentor style 1800 leaflet valve implant. Introducing a metal catheter into the leaflet valve fills this type of implant. These particular implants had a high deflation rate, like leaflet valve implants from other manufacturers. The deflations were frequently partial, and were likely due to valve failure. A similar mechanism that caused these partial failures may have also allowed fluid from the implant pocket to pass into the lumen of these implants in cases 2 and 3

1. The implants were initially filled with a hypertonic solution. This would create an osmotic gradient, which would allow water to enter the implant. If this were the only mechanism, then the resulting solution would likely be clear and transparent. It would not contain measurable glucose, protein, uric acid or cellular fragments $(2,6,7)$.

2. Water, protein and glucose could pass through the intact elastomeric shell, through a process known as 'colloid osmotic swelling' $(4,5)$. Over time, protein and glucose could penetrate the implant to the lumen. The increased osmolarity could then result in autoinflation by osmosis of water.

3. Mechanical alterations of the valve could allow glucose, protein, uric acid and cellular elements to enter into the lumen. These substances would not pass through an intact elastomeric shell. In the 17 reported implants, and in cases 2 and 3 of the present study, glucose and cellular elements were present in this group of implants. In addition, the fluid in the implants was brownish yellow and turbid (2).

4. The salt used in the texturing process of the outer surface of textured implants could contribute to the concentration of sodium chloride in the implant (2).

In the present study, none of the three patient implants had a textured surface. Therefore, theory 4 can be eliminated. Similarly, theory 2 can also be eliminated because Frisch $(6,7)$ has now demonstrated that colloid osmotic swelling would not be a factor causing autoinflation because glucose, proteins and cellular elements would not be able to penetrate an intact elastomeric shell.
Case 1 - Hypertonic filling solution: The most likely explanation for the autoinflation observed in case 1 (Simaplast implant) is that the original filling solution had an osmolality that was higher than that of normal saline. This would create an osmotic gradient across the elastomeric wall, and would allow progressive passage of water into the implant over time $(6,7)$. Analysis of the fluid in the implants in the present study would support this explanation (Table 1). The larger (left) implant had a higher osmolality than the right side (407 mmol $/ \mathrm{kg}$ versus $304 \mathrm{mmol} / \mathrm{kg}$ ), and a higher concentration of sodium and chloride $(215 \mathrm{mmol} / \mathrm{L}$ and $202 \mathrm{mmol} / \mathrm{L}$ versus $160 \mathrm{mmol} / \mathrm{L}$ and $153 \mathrm{mmol} / \mathrm{L}$, respectively). The values of the right implant approximated those of normal saline.

Calculations indicate that the left implant was likely to be originally filled with a solution of sodium chloride that was twice as concentrated as 'normal saline'. This would have provided an osmotic gradient, facilitating autoexpansion by diffusion over time. Further calculations show that under the conditions existing in the left implant, a much larger volume gain than that actually observed should have occurred. Because this was not the case, it appears likely that tissue resistance from the Baker class IV contracture limited expansion. There were no detectable amounts of tissue fluid components in the expanded implant. In addition, the implant fluid was completely clear. These findings provide further evidence that there was no mechanical valve failure, which could have allowed the passage of these components into the lumen of the implant.

It is likely that small changes in implant size may be quite common with implanted saline implants. These can result from variations in sodium chloride concentrations in United States Pharmacopoeia (USP) sodium chloride injection (13) the solution generally recommended for use in saline-filled implants. The USP specifies that the solution contains $95 \%$ to $105 \%( \pm 5 \%)$ of the labelled amount of sodium chloride. A $300 \mathrm{~mL}$ implant could, therefore, have a volume range between $285 \mathrm{~mL}$ and $315 \mathrm{~mL}$. Using a single batch of USP sodium chloride injection should prevent size differences in bilateral cases. Small variations in sodium chloride concentrations may have a large effect on implant volumes. Isotonic saline with an extra $0.9 \mathrm{~g}$ of sodium chloride per $100 \mathrm{~mL}$ would result in doubling of the implant size (6).

Cases 2 and 3 - Alteration of leaflet valve mechanism: The two saline implants in the present study (cases 2 and 3) were Mentor style 1800 implants, which have leaflet valves (Figure 8). Introducing a metal catheter into the leaflet valve mechanism fills this type of implant. These particular implants, like all other leaflet valve saline implants, are now known to have a high deflation rate (19-21). Similar high deflation rates have also been found among leaflet valve saline-filled implants that were made by other manufacturers, including Dow Corning Corporation (USA) and McGhan, INAMED Aesthetics (USA) $(19,20)$. The failure of these leaflet valve saline-filled implants was likely due to a faulty valve mechanism, possibly secondary to fibrous tissue growing into the leaflet valve $(19,21)$. These deflations were frequently partial. The same mechanism that caused these partial deflations of leaflet valve implants may have allowed fluid from the implant pocket to pass into the lumen of the two autoinflated leaflet valve implants in the present study. It is interesting that case 3 had autoinflation on the right side, and partial deflation on the left 
side. Both of these implants were from the same lot number. It should be pointed out that Mentor style 1800 implants have not been manufactured for over 10 years. Autoinflation has not been seen with the current Mentor style 1600 implants.

In the present study, the fluid in the leaflet valve implants demonstrated significant levels of uric acid (Table 1). Uric acid is the final oxidation product of purine metabolism. It is too large to pass through the elastomeric shell. It may have passed through the altered valve, or it may have been produced from the metabolism of other substances that had passed through the altered valve.

In 1982, Austad and Rose (17) described a self-inflating tissue expander using the concept of autoinflation. They demonstrated that a large excess amount of sodium chloride was necessary to obtain rapid autoinflation (over 110 days). They showed that the inflation rate through an implant with a $0.25 \mathrm{~mm}$ thick elastomeric shell was linear up to 110 days, when the implant contained sufficient sodium chloride to keep it saturated throughout the course of inflation. Near-isotonic implants, at full inflation, expanded much more slowly. A German study, by Ronert et al (22), has taken this concept further. They have developed an 'osmotic tissue expander', which contains hydrogel. Once implanted, it absorbs body fluids producing gradual swelling of the device, which is completed in six to eight weeks. Over a four-year period, this expander was used in 58 patients, in many areas of the body. It is interesting to note that in 1977, Arrillaga et al (18) proposed a method to achieve shrinkage of an implant by water loss over time from a deliberately hypotonic solution in the implant, to compensate for capsular contracture.

The Simaplast implants in the present study are unique because they had remained clinically intact after 23 years in situ, they were calcified on their anterior surface, the left side had undergone a spontaneous increase in volume from $200 \mathrm{~mL}$ to $290 \mathrm{~mL}$ and bacteria were cultured from the fluid inside both implants.

Calcification of saline implants is a rare phenomenon $(16,23,36)$. Peters et al $(16)$ have analyzed the calcification properties of Simaplast implants in an earlier publication. Ultrastructure analysis showed large, electron-dense aggregates of crystals with individual electron-dense crystals measuring approximately $40 \mathrm{~nm} \times 10 \mathrm{~nm} \times 10 \mathrm{~nm}$. Electron diffraction demonstrated the D-spacings characteristic of calcium hydroxyapatite crystals. This mineralization may result from abrasion of the anterior aspect of the implant surface against the overlying capsule. This may explain the increased calcification on the left side because the capsular contracture on that side (Baker class IV versus Baker class II on the right side) (Figure 3) would be expected to increase abrasion.

A total of 20 autoinflated implants have been reported in the world literature $(2-10)$. Of these, 13 were double-lumen textured implants, five were single-lumen smooth-walled saline implants and two were single-lumen textured saline implants. Of the 20 implants, only three had a clear transparent solution at presentation (3) which did not contain measurable levels of glucose, protein and cellular elements. These patients had likely undergone autoinflation because their initial injection fluid was hypertonic. The other 17 implants contained a very viscous brownish yellow fluid, which contained glucose, protein and cellular elements. These substances would not have been able to pass through an intact elastomeric shell. They were most likely associated with mechanical valve alterations, which could allow them to enter the implant through the altered valve.

In the present study, broth cultures from the fluid inside the Simaplast implants grew $S$ cohnii from the left side and $S$ cohnii, $P$ acne, and diphtheroid bacilli from the right side. Only a few other studies have reported positive cultures of bacteria inside saline-filled implants or tissue expanders (24-26). Staphylococcus aureus, $S$ epidermidis, $P$ acne and diphtheroid bacilli are a part of the normal endogenous flora of both skin and breast tissue (27) and are also known to colonize the capsules of silicone gel-filled implants (28). These organisms may have been introduced during the original augmentation surgery, either from the breast tissue or from the skin. Young et al (29) have demonstrated that several types of bacteria can grow and reproduce in a restricted saline environment for extended periods of time. There are no known previous reports of $S$ cohnii colonizing breast implant capsules or surviving in the filling solution of inflatable implants. This organism has been associated with the development of urinary tract infections in patients in developing countries (30) and has been responsible for the development of pneumonia in an HIV-infected patient (31). There is one report of this organism being cultured from a revision arthroplasty (32).

It should be pointed out that there are other potential causes of unilateral breast enlargement after insertion of salinefilled implants. These conditions are also very rare. They include late infection (32), late capsular hematoma (33) and breast lymphoma (34). All of these diagnoses should be considered in patients with unilateral breast enlargement after breast augmentation.

ACKNOWLEDGEMENT: The present study was funded by a grant from the Plastic Educational Foundation of the American Society of Plastic and Reconstructive Surgeons.

\section{REFERENCES}

1. Kessler DA. The basis of the FDA's decision on breast implants. N Engl J Med 1992;326:1713-5.

2. Signorini M, Grisotti A, Ponzielli G, Pajardi G, Gilardino P. Self-expanding prostheses complicating augmentation mammoplasties. Aesthetic Plast Surg 1994;18:195-9.

3. Botti G, Villedieu R. Postoperative self-expansion in augmentation mammoplasty. Plast Reconstr Surg 1994;93:1310.

4. Robinson OG Jr, Benos DJ. Spontaneous autoinflation of saline mammary implants. Ann Plast Surg 1997;39:114-8.

5. Robinson G Jr, Benos DJ. Spontaneous autoinflation of saline mammary implants. Ann Plast Surg 1998;40:101.

6. Frisch E. Spontaneous autoinflation of saline mammary implants: Invited discussion. Ann Plast Surg 1997;39:118-21.

7. Frisch E. Spontaneous autoinflation of saline mammary implants: Invited discussion. Ann Plast Surg 1998;40:101-3.

8. Tuncali D, Ozgur F. Spontaneous autoinflation of saline-filled mammary implants: Postoperative volume determination by magnetic resonance imaging. Aesthetic Plast Surg 1999;23:437-42.

9. Ketene M, Saray A, Kara SA. Unilateral osmotic swelling in textured, single-lumen, saline-filled mammary implants: Clinical and MRI findings. Aesthetic Plast Surg 2002;26:206-10.

10. Chien CH, Ding XZ, Yang ZS. Spontaneous autoinflation and deflation of double-lumen breast implants. Aesthetic Plast Surg 2006;30:113-7.

11. Product Information Brochure - Simaplast Implant. Yonkers: Simaplast Inc, 1967.

12. Arion HG. Presentation d'une prosthese retra mammaire. J Soc Fr Gynecol 1965;2:5-8.

13. The United States Pharmacopoeia XXI. United States Pharmacopoeias Convention Inc, 1990:1255. 
14. Williams JE. Experiences with a large series of silastic breast implants. Plast Reconstr Surg 1972;49:253-8.

15. Tabari K. Augmentation mammaplasty with Simaplast implant. Plast Reconstr Surg 1969;44:468-70

16. Peters W, Smith D, Lugowski S, Pritzker K. Simaplast inflatable breast implants: Evaluation after 23 years in situ. Plast Reconstr Surg 1999;104:1539-44,1545.

17. Austad ED, Rose GL. A self-inflating tissue expander. Plast Reconstr Surg 1982;70:588-94

18. Arrillaga Z, Ersek RA, Baricos WM, Ryan RF. Method for the prevention of firm breasts from capsular contraction. Plast Reconstr Surg 1977;60:753-4.

19. Peters W. Failure properties of leaf valve inflatable saline breast implants. Can J Plast Surg 1997;5:241-5.

20. Peters W. The evolution of breast implants. Can J Plast Surg 2002;10:223-36.

21. Umansky C. Plugs on the filling valves of saline breast implants. Plast Reconstr Surg 1996;98:914.

22. Ronert MA, Hofheinz H, Manassa E, Asgarouladi H, Olbrisch RR. The beginning of a new era in tissue expansion: Self-filling osmotic tissue expander - four-year clinical experience. Plast Reconstr Surg 2004;114:1025-31

23. Schmidt GH. Calcification bonded to saline-filled breast implants. Plast Reconstr Surg 1993;92:1423-5.

24. Truppman ES, Ellenby JD, Schwartz BM. Fungi in and around implants after augmentation mammaplasty. Plast Reconstr Surg 1979;64:804-6.

25. Nordstrom RE. Antibiotics in the tissue expander to decrease the rate of infection. Plast Reconstr Surg 1988;81:137-8. (Lett)

26. Liang MD, Narayanan K, Ravilochan K, Roche K. The permeability of tissue expanders to bacteria: An experimental study. Plast Reconstr Surg 1993;92:1294-7.
27. Thornton JW, Argenta LC, McClatchey KD, Marks MW. Studies on the endogenous flora of the human breast. Ann Plast Surg 1988;20:39-42.

28. Peters W, Smith D, Fornasier V, Lugowski S, Ibanez D. An outcome analysis of 100 women after explantation of silicone gel breast implants. Ann Plast Surg 1997;39:9-19.

29. Young VL, Hertl MC, Murray PR, Jensen J, Witt H, Schorr MW. Microbial growth inside saline-filled breast implants. Plast Reconstr Surg 1997;100:182-96.

30. Orrett FA, Shurland SM. Significance of coagulase-negative staphylococci in urinary tract infections in a developing country. Conn Med 1998;62:199-203.

31. Mastroianni A, Coronado O, Nanetti A, Manfredi R, Chiodo F. Community-acquired pneumonia due to Staphylococcus cohnii in an HIV-infected patient: Case report and review. Eur J Clin Microbiol Infect Dis 1995;14:904-8.

32. Crichton PB, Anderson LA, Phillips G, Davey PG, Rosley DI. Subspecies discrimination of staphylococci from revision arthroplasties by ribotyping. J Hosp Infect 1995;30:139-47.

33. Basile AR, Basile F, Basile AV. Late infection following breast augmentation with textured silicone gel-filled implants. Aesth Surg J 2005;25:249-54.

34. Gaudet G, Friedberg JW, Weng A, Pinkus GS, Freedman AS. Breast lymphoma associated with breast implants: Two case-reports and a review of the literature. Leuk Lymphoma 2002;43:115-9.

35. Dennis WE, Larson WD. Permeation of Silicone Elastomers. Midland: Dow Corning Corporation.

36. Peters W, Smith D, Lugowski S, Pritzker K, Holmyard D. Calcification properties of saline-filled breast implants. Plast Reconstr Surg 2001;107:356-63 